\title{
Surfactant Surface Tension Effects on Promoting Hydrate Formation: An Experimental Study Using Fluorocarbon Surfactant (Intechem-01) + SDS Composite Surfactant
}

\author{
Lin Zhang, Shidong Zhou, Shuli Wang, Lei Wang, Jianmin Li
}

China Jiangsu Key Laboratory of Oil \& Gas Storage and Transportation Technology, School of Petroleum Engineering, Changzhou University, Changzhou, China.

Email: togetherlin1989@163.com, zsd@cczu.edu.cn,ws1@cczu.edu.cn,576762261@qq.com,749152445@qq.com

Received March 11 ${ }^{\text {th }}, 2013$; revised April 14 ${ }^{\text {th }}, 2013$; accepted May 12 $2^{\text {th }}, 2013$

Copyright (C) 2013 Lin Zhang et al. This is an open access article distributed under the Creative Commons Attribution License, which permits unrestricted use, distribution, and reproduction in any medium, provided the original work is properly cited.

\begin{abstract}
The investigation of surface tension is a very important task for gas hydrate studying. Surfactants can effectively reduce the surface tension, improve the gas storage capability of hydrate and increase the formation rate, shorten the induction time. The objective of this study were to obtain a better understanding of the role of surface tension on hydrate formation and build gas hydrate models involve surfactant. In this study it was highlighted that the surface tension of Intechem-01 + SDS composite surfactants in natural gas hydrate promotion system and the change rules at different temperatures, concentration and proportion. According to the results of experiment, the surface tension of composite surfactants decreased with the increase of Intechem-01. The best cooperating effect was observed in proportion (Intechem- 01 content) of $0.6-0.7$, where the surface tension was the lowest. In this proportion range, the composite surfactants showed the same effect to pure fluorine carbon surfactant. The study shown the surface tension of composite surfactants decreased with the rise of temperature, and they were in a linear relationship within a certain range. Surface tension of composite surfactants decreased with the increase of surfactant concentration, however, it was no longer decreased above critical micelle concentration $(\mathrm{CMC})$. The fitting equation of surface tension with various factors has been obtained.
\end{abstract}

Keywords: Natural Gas Hydrate; Hydrate Promoter; Surfactant; Surface Tension; Fitting Equation

\section{Introduction}

Natural gas hydrate has huge gas storage capacity and the technology of natural gas hydrate storage and transportation offers a new method for energy storage and transportation. Compared with Liquefied Natural Gas (LNG) and Compressed Natural Gas (CNG) natural gas hydrate (NHG) has obvious advantages, which costs less and can be operated stably. Gudmundsson et al. [1] confirmed that methane gas can be stored long-term in hydrate above $258.15 \mathrm{~K}$ at atmospheric pressure, while LNG storage at $T=111.15 \mathrm{~K}$, and the price of natural gas hydrate device is only $25 \%$ of LNG. Using Sodium dodecyl sulfate (SDS), tetradecyl sodium sulfate (STS) and sodium hexadecyl sulfate (SHS) as contrast experiments, Okutani K [2] discovered STS at concentration of 100 ppm had the same positive effect to $1000 \mathrm{ppm}$ SDS. Jeffry Yoslim's experiment [3] studied the effect of SDS on methane-propane gas hydrate and found that molar gas consumption increased 14 times in 242 - 2200 ppm SDS compared with pure water system. The results were caused by gas liquid contact area increasing since porous hydrate forming. H. Ganji [4] found that the hydrate formation rate increased by 35 times in 500 ppm SDS, gas storage ability increased by one time. At temperature of $274.15 \mathrm{~K}$ and pressure of $3.5-4.0 \mathrm{Mpa}$, Young-Ah Kwon [5] used various anionic surfactant with different length of carbon chain $(\mathrm{C} 8, \mathrm{C} 10, \mathrm{C} 12)$ as hydrate promoter and found surfactant with shorter carbon chain had stronger promote ability. Multiple chain sulfate surfactant had had better gas storage capacity than SDS even at low concentrations, because of their lower critical micelle concentration (CMC) and special surface tension. Using drops method, Hu Luo et al. [6] measured the interfacial tension of ethylene surfactant solution in different temperature and pressure, and studied the influence of pressure for $\mathrm{CMC}$, the results of the study showed that 
the CMC decreased with increasing pressure. Y. Zhong [7] investigated the effect of SDS on methane hydrate formation, they found CMC of SDS is $242 \mathrm{ppm}$.

As mentioned above, the effect of some surfactant has been studied, however, the current researches mostly limited to the influence of factors such as surfactant dosage and concentration. The promotion mechanism of additives is not very clear yet. The key effect of surfactant is that it reduces the gas-liquid interface surface tension so that the diffusion resistance between two phase is reduced and the gas molecules solubility is increased, as a consequence, better mass transfer effects is gained.

This study was performed based on previous study [8] which obtained the conclusion that using composite promoting agents of $\mathrm{CP}$ (chemically pure) + SDS and methylcyclohexane $(\mathrm{MCH})+$ SDS can reduce the phase equilibrium temperature and shorten the induction time. The surface tension of Intechem-01 + SDS composite surfactants and its changes with temperature, concentration and proportion has been investigated. The aim of the study has been to reveal the essence of surfactant effects, which is significance to find the relationship between gas hydrate formation rate and surfactant kinds, dosage and concentration and establish new hydrate kinetics model containing surfactant factors.

\section{Description of Experiments}

\subsection{Experimental Apparatus and Materials}

The experimental apparatus produced by Shanghai Fangrui Inc is a QBZY series automatic surface tension determine instrument. Laboratory reagent are Perfluorinated alkyl ether glycol amine salt type anionic fluorocarbon surfactant (Intechem-01), industrial grade,active matter content $\geq 99 \%$ and sodium dodecyl sulfate (SDS), industrial grade, active matter content $\geq 86 \%$.

\subsection{Experimental Procedure}

Composite Surfactants whose ratios (the proportion of fluorocarbon surfactant in the total active agent quality) are $0,0.1,0.2,0.3,0.4,0.5,0.6,0.7,0.8,0.9,1$, respectively were prepared before experiment. 0 represents for pure SDS, 1 represents for pure fluorocarbon surfactant. Solution concentration is between $0.01 \%-0.9 \%$. 2. Surface tension values of measured samples at different concentrations and proportions, temperatures of $283.15 \mathrm{~K}$, $288.15 \mathrm{~K}, 293.15 \mathrm{~K}, 298.15 \mathrm{~K}$ and $303.15 \mathrm{~K}$, respectively, were measured by tensiometer. Record the experiment data.

\section{Results and Discussion}

\subsection{Surface Tension Properties of Pure Surfactant Liquid}

In Figure 1(a), is represented the surface tension changes of Sodium dodecyl sulfate along with the concentration at $298.15 \mathrm{~K}$. As is shown, the critical micelle concentration $(\mathrm{CMC})$ of sodium dodecyl sulfate is $1.5 \%$, the lowest surface tension is $34 \mathrm{mN} / \mathrm{m}$ [9]. Figure 1(b), is represented the surface tension changes of pure fluorocarbon surfactant (Intechem-01) along with the concentration at $298.15 \mathrm{~K}$, the critical micelle concentration is about $0.08 \%$, and the lowest surface tension is $16.8 \mathrm{mN} / \mathrm{m}$. By comparison, it is known that the fluorocarbon surfactant shows better surface activity in low concentration.

Figure 2 shows the surface tension changes of Intechem- 01 solution along with concentration at different temperatures, and concentration between $0 \%-1 \%$, The higher temperature is, the lower surface tension, and the surface activity effects of solution are more evident The higher concentration is, the lower surface tension is, the surface tension has dropped sharply at concentration of $0 \%-0.1 \%$ and did not reduced when the concentration exceeds $0.1 \%$. The lowest surface tension is $16.2 \mathrm{mN} / \mathrm{m}$ and $17.1 \mathrm{mN} / \mathrm{m}$ at $303.15 \mathrm{~K}$ and $283.15 \mathrm{~K}$. Fluorocarbon surfactant is better than the hydrocarbon surfactant in terms of amount and activity.

\subsection{Surface Tension Properties of Composite Surfactant Solutions}

Pure Intechem-01 solution has good surface capability at very low concentrations, given its expensive price, we used composite surfactant of fluorocarbon surfactant and hydrocarbon surfactants such as SDS.

When Intechem-01 and SDS are mixed, the oxygen combines with $\mathrm{H}+$ and owns a amount of positive charge [10], molecular interactions are strengthen. It is easy to make a mixed micelle with better effect of combination. The above conclusion can be concluded in Figures 3-6.

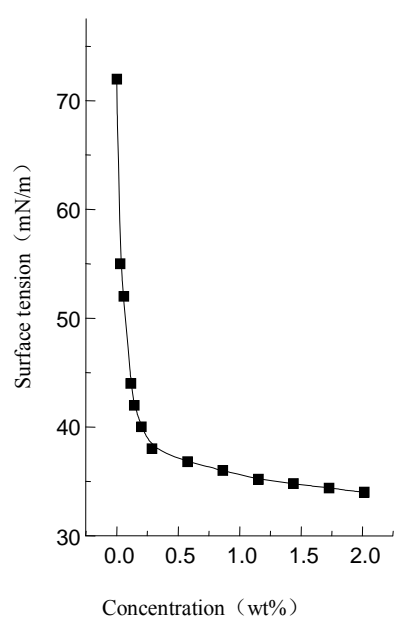

(a)

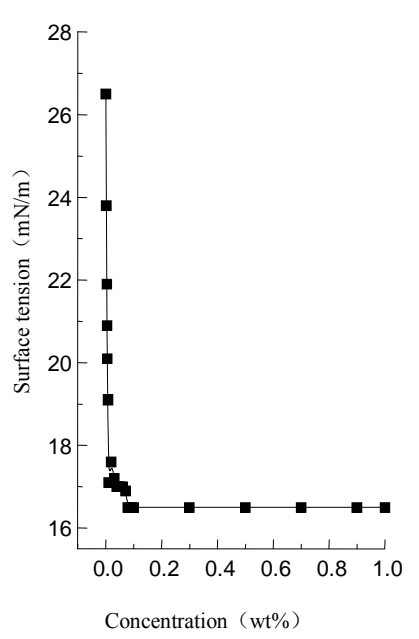

(b)
Figure 1. Surface tension of pure SDS solution and pure Intechem-01 solution. 


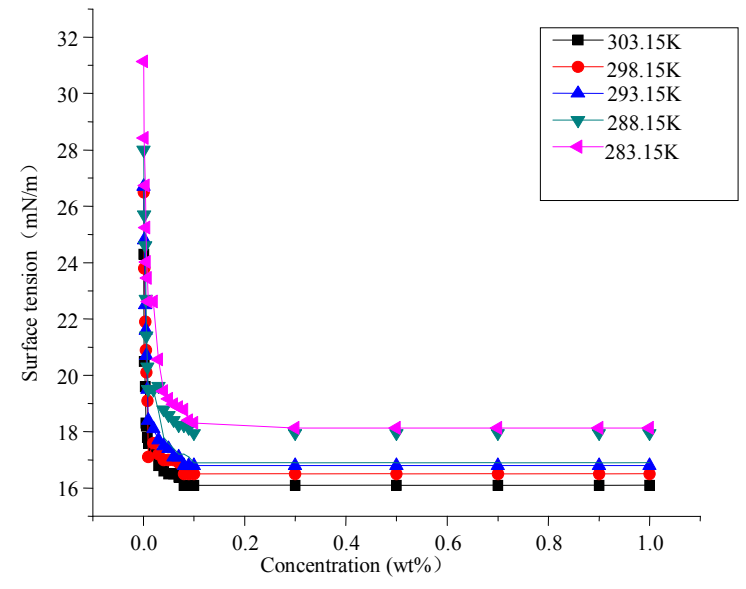

Figure 2. Surface tension of pure Intechem-01 solution with the concentration at different temperature.

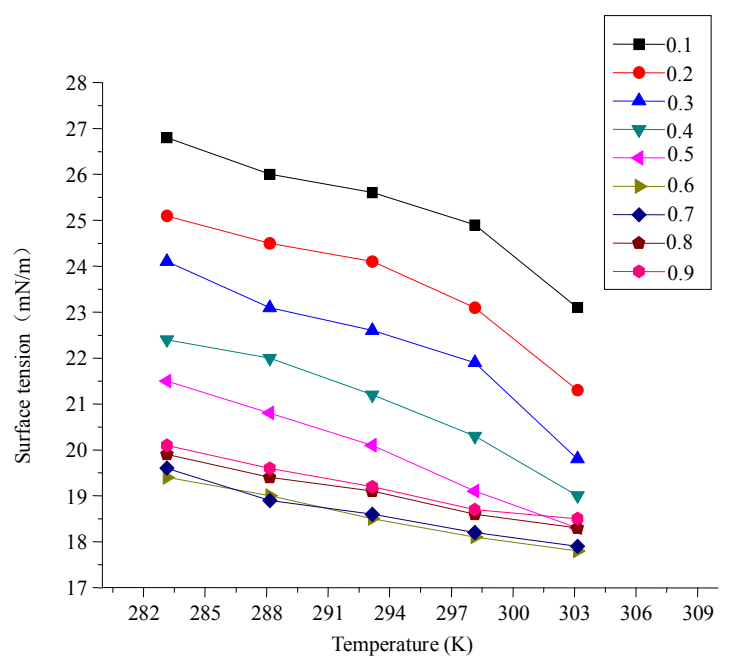

Figure 3. Surface tension in different ratio at a concentration of $0.01 \%$.

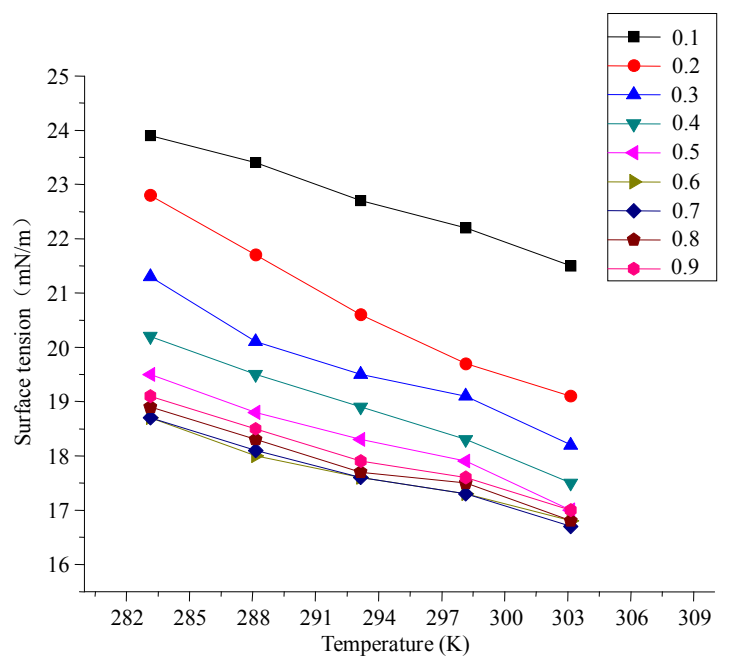

Figure 4. Surface tension in different ratio at a concentration of $\mathbf{0 . 0 5 \%}$.

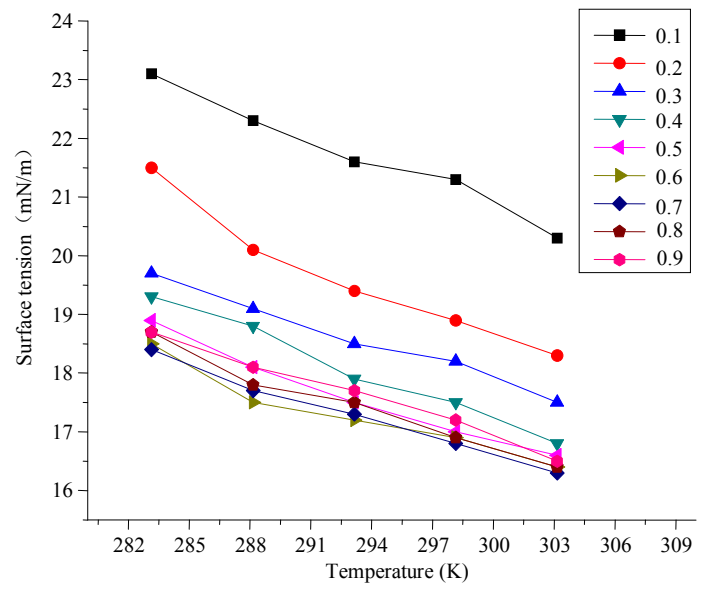

Figure 5. Surface tension in different ratio at a concentration of $\mathbf{0 . 0 7 \%}$.

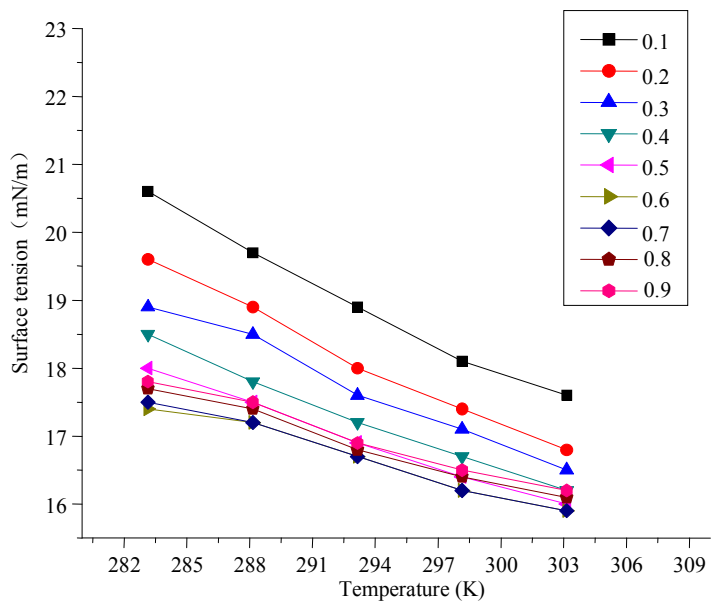

Figure 6. Surface tension in different ratio at a concentration of $0.1 \%$.

Usually fluorocarbon surfactants have more surface adsorption capability than hydrocarbon surfactant [11]. The fluorocarbon surfactant is readily to be absorbed in surface saturated adsorption layer of combination solution than hydrocarbon surfactant, which makes solution tends to shows low surface activity like fluorine carbon surfactant. But, the hydrocarbon surfactant with too long hydrocarbon chain is not fit to be chosen, because the overlong hydrocarbon chain can make solution more like hydrocarbon surfactant and increase the surface tension. Two kinds of surfactant with similar hydrophobic chain length had better be chosen as far as possible [12].

\subsection{Incidence Formula}

\subsubsection{Incidence Formula of Surface Tension and Temperature}

1) Linear correlation

From Figures 3-6, it is easy to see surface tension and 
temperature are approximate a linear relationship. With the increase of temperature gas, fluid properties and the corresponding molecule force are get to closer, surface tension is decreased, $\sigma$ is zero at the critical point. When the contrast state temperature $T_{r}$ is in range of $0.4-0.7$, simple linear correlations are commonly used.

$$
\sigma=a+b T
$$

where $T$ is the absolute temperature, when the concentration is $0.01 \%$, at various proportions, the use Equation (1) to associate surface tension and temperature.

According to Table 1 and Figure 7, it is known that at certain temperature range, when the concentration of sodium dodecyl sulfate + fluorocarbon surfactant mixture is $0.01 \%$, the results of surface tension and temperature measured with platinum plate method (in atmospheric

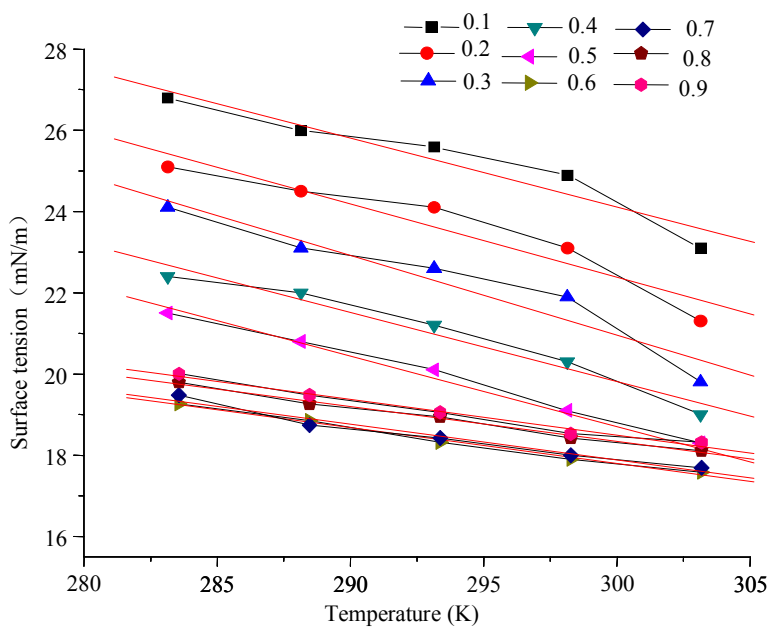

Figure 7. Relationship between surface tension of combination solution and temperature $(\mathbf{0 . 0 1 \% )}$.

Table 1. The related results of surface tension of combination solution and temperature $(\mathbf{0 . 0 1 \% )}$.

\begin{tabular}{cccccc}
\hline proportion & $\mathrm{a}$ & error & $\mathrm{b}$ & error & $\mathrm{SD}$ \\
\hline 0.1 & 75.116 & 8.315 & -0.17 & 0.028 & 0.448 \\
0.2 & 76.387 & 9.261 & -0.18 & 0.032 & 0.499 \\
0.3 & 79.757 & 9.432 & -0.196 & 0.032 & 0.509 \\
0.4 & 70.816 & 5.491 & -0.17 & 0.018 & 0.296 \\
0.5 & 67.450 & 1.885 & -0.162 & 0.006 & 0.102 \\
0.6 & 42.598 & 1.123 & -0.082 & 0.004 & 0.061 \\
0.7 & 42.678 & 2.418 & -0.082 & 0.008 & 0.130 \\
0.8 & 42.512 & 1.173 & -0.08 & 0.004 & 0.063 \\
0.9 & 43.258 & 1.759 & -0.082 & 0.006 & 0.0949 \\
\hline
\end{tabular}

where $\mathrm{a}, \mathrm{b}$ are fitting parameters; a nodal increment; $\mathrm{b}$ slope; Error is the fitting standard error parameters; SD is Standard deviation. pressure) show good linear relationship, linear correlation coefficient are greater than 0.96 . Measured values and the fitting line can be a very good conform, Equation (1) can be used to associate and forecast

2) Corresponding state index correlation

When the temperature range is a little higher corresponding state index incidence Equation (2) can be used to relate temperature.

$$
\sigma=\sigma_{1}\left(\frac{1-T_{r}}{1-T_{r 1}}\right)^{n}
$$

where $\sigma_{1}$ is surface tension in reduced temperature $T_{r 1}$, $T_{r 1}$ is reduced temperature, $n$ is correlation coefficient (according to different types of solution $\mathrm{n}$ can take fixed value)

\subsubsection{Incidence Formula of Surface Tension and Concentration}

Here lists the relationship between surface activity and concentration at temperature of $298.15 \mathrm{~K}$.

Figure 8 is represented the relationship between surface tension and concentration at different proportion at the temperature of $298.15 \mathrm{~K}$. It can be concluded that surface tension and concentration are positive correlation at low concentration. As is shown in Figures $\mathbf{1}$ and 2, surface tensions increase with decreasing of surfactant concentrations at the beginning, but when concentration exceeded critical micelle concentration (CMC), surface tension did not change with concentration. At certain temperature, the relationship of surface tension of pure Intechem-01 surfactant solutions and concentration shown in Figure 2 was related by Origin7.5 [13]. According to the change rules of surface tension along with concentration, decaying exponential function Equation (3)

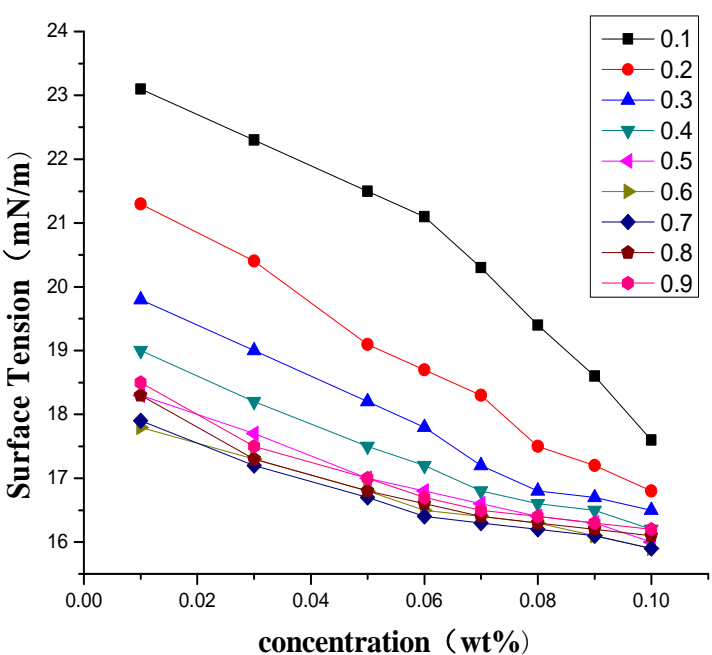

Figure 8. Relationship between surface tension and concentration at different proportion $(298.15 \mathrm{~K})$. 
can be used to relate concentration.

$$
\sigma=\sigma_{0}+\exp \left(-x / t_{1}\right)
$$

The experimental data shown in Table 2 and Figure 9 have good fitting relationship, the relationship between surface tension and the concentration is index the attenuation relationship, nonlinear relationship.

\subsubsection{Incidence Formula of Surface Tension and Proportion}

Here only lists the relationship of surface activity and ratio at a temperature of $303.15 \mathrm{~K}$.

Figure 10 demonstrates the synergistic effect of SDS and fluorocarbon surfactant. When the ratio is between $0.1-0.6$, surface tension decreases with the increase of the content of Intechem-01. But the ratio is between 0.6 1 , surface tension rises slightly with the increase of the content of Intechem-01. It is concluded it is incorrect that the more of high performance surfactant, the better of ratio effect. The best ratio result is gotten at ratio of 0.6 0.7 .

1) Polynomial incidence formula of Solution proportion

Surface tension and proportion are second-degree parabola relationship, polynomial Equation (4) can be used to fit.

$$
\sigma=\sigma_{0}+A x+B T^{2}
$$

where $A, B$ is correlation coefficient, related results and fitting graphics are shown in Table 3 and Figures 11-12, fitting effect is good.

Table 2. The related results of surface tension.

\begin{tabular}{cccccc}
\hline $\mathrm{T}(\mathrm{K})$ & $\sigma 0$ & $\mathrm{~A} 1$ & $\mathrm{t} 1$ & $\mathrm{Chi}^{2} / \mathrm{Dof}$ & $\mathrm{R}^{2}$ \\
\hline 298.15 & 16.725 & 11.829 & 0.005 & 0.163 & 0.981 \\
\hline
\end{tabular}

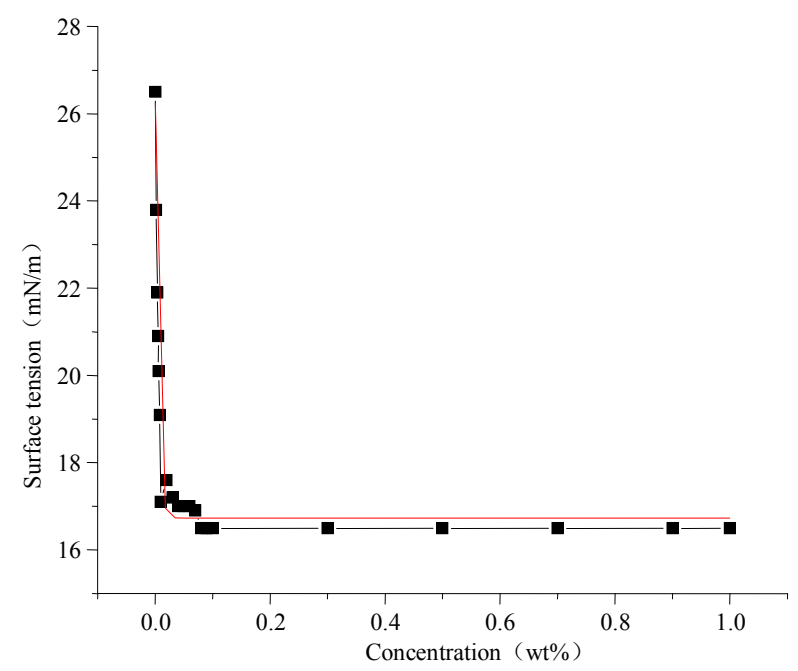

Figure 9. Fitted curve of surface tension (298.15 K).

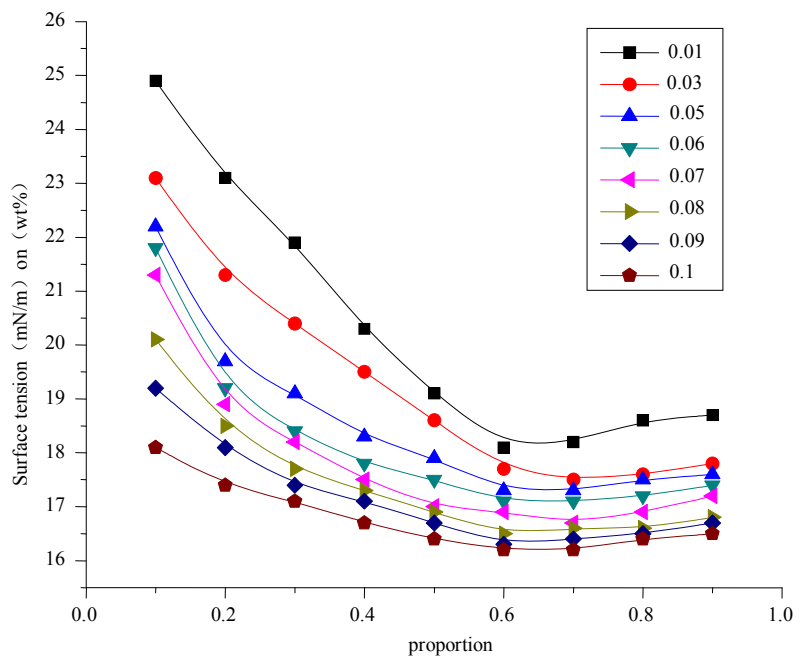

Figure 10. Relationship between surface tension and proportion in different concentrations $(303.15 \mathrm{~K})$.

Table 3. Correlation results of surface tension and proportion at different concentration (303.15 K).

\begin{tabular}{cccccc}
\hline Concentration (\%) & $\sigma_{0}$ & $A$ & $B$ & R-square & SD \\
\hline 0.01 & 24.986 & -21.504 & 16.104 & 0.995 & 0.151 \\
0.03 & 23.898 & -19.699 & 14.199 & 0.991 & 0.193 \\
0.07 & 21.286 & -15.636 & 11.786 & 0.946 & 0.353 \\
0.08 & 21.093 & -13.596 & 9.946 & 0.978 & 0.201 \\
\hline
\end{tabular}

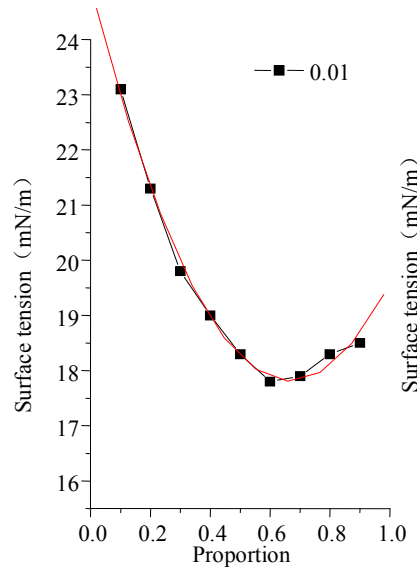

(a)

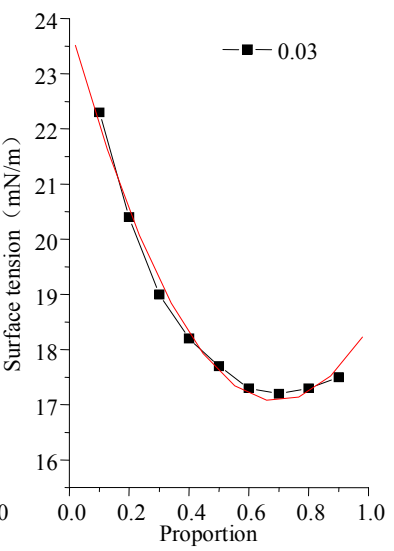

(b)
Figure 11. Measurement data and fitting relationship of surface tension (concentration $0.01 \%$ and $0.03 \%, 303.15 \mathrm{~K}$ ).

2) Incidence formula of temperature and proportion

The relationship between surface tension temperature and proportion can be fitted by quadratic polynomial. Parts of related results of SDS and Intechem- 01 are shown in Table 4. If temperature range is low, the quadratic component in Equation (5) can be deleted. 


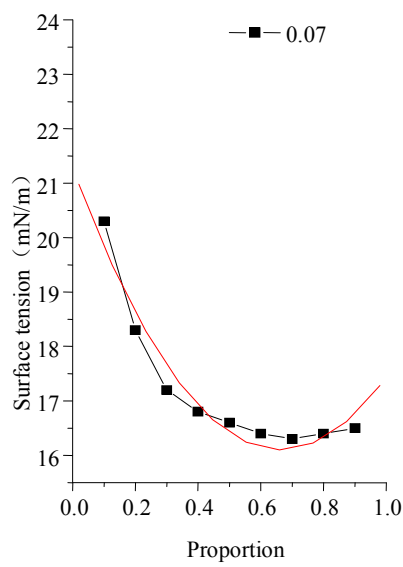

(a)

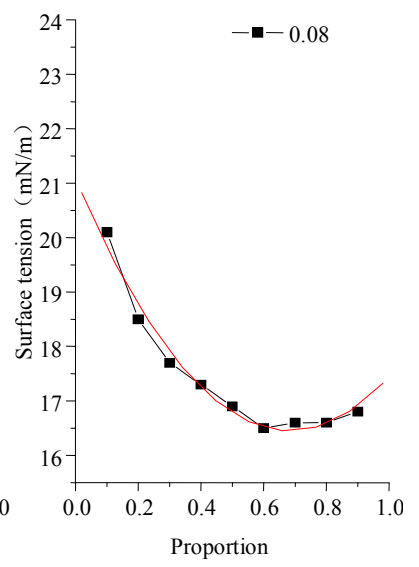

(b)
Figure 12. Measurement data and fitting relationship of surface tension (concentration $0.07 \%$ and $0.08 \%, 303.15 \mathrm{~K}$ ).

Table 4. Polynomial fitting results.

\begin{tabular}{ccccccc}
\hline Concentration (\%) & $A_{0}$ & $A_{1}$ & $A_{2}$ & $B_{0}$ & $B_{1}$ & $B_{2}$ \\
\hline 0.06 & 65.675 & 45.274 & 27.939 & 0.143 & 0.091 & 0.048 \\
0.07 & 67.697 & 53.040 & 35.764 & 0.153 & 0.121 & 0.077 \\
0.08 & 72.058 & 75.726 & 56.696 & 0.171 & 0.208 & 0.156 \\
0.09 & 74.418 & 89.612 & 70.398 & 0.182 & 0.263 & 0.208 \\
0.1 & 71.818 & 73.452 & 44.201 & 0.178 & 0.220 & 0.129 \\
\hline \multicolumn{7}{c}{} \\
& $\sigma=\sum_{i-0}^{2}\left(A_{i} x^{i}+B_{i} x^{i} T\right)$ & & &
\end{tabular}

where $A$ and $B$ are fitting parameters.

Fitting parameters of concentration $0.1 \%$ were substituted into Equation (5) and Equation (6) is obtained.

$$
\begin{aligned}
\sigma & =71.818-0.178 T-73.45 x \\
& +0.22 T x+44.201^{2}-0.129 T x^{2}
\end{aligned}
$$

\section{Conclusions}

1) Surface tension was considered in natural gas hydrate formation dynamic model, which can more accurately analysis and forecast hydrate formation process and calculate change process of phases. The minimum surface tension of fluorocarbon surfactant was $16.8 \mathrm{mN} / \mathrm{m}$ in this experiment, and critical micelle concentration was $0.08 \%$. The surface tension was reduced effectively when SDS blends with fluorocarbon surfactant, which reduces usage amount of fluorocarbon surfactant and cut the expenditure. In best ratio of $0.6-0.7$ conditions, the surface tension was the same with pure fluorocarbon surfactant.

2) It was obtained that surface tension of composite surfactants and temperature were linear relation in a range, and the linear correlation coefficients were above
0.96; Solution surface tension and concentration were attenuation function index relationship, surface tension of composite surfactants decreased with increasing concentration. Exceeding the critical micelle concentration (CMC), Surface tension won't change with concentration. And the linear correlation coefficients were above 0.94. Surface tension and proportion were two-polynomial relationship and it decreased with increasing proportion. It was lowest at the best ratio, the linear correlation coefficients were also above 0.94 .

3) Because the high pressure in natural gas hydrate reactor, pressure factors effects on surface tension must be taken in to consideration. It was more accurate that using contrast state method and the structure method to forecast surface tension, which can effectively solve difficulties of gas hydrate solution surface tension measurement in high pressure.

\section{Acknowledgements}

The authors thank the financial support from the National Science Foundation of China (No.51176015) and petroleum technology innovation foundation of China (2011 D-5006-0606).

\section{REFERENCES}

[1] J. S. Gudmundsson, A. A. Khokhar and M. Parlaktuna, Proceedings of 67th Annual Technical Conference and Exhibition of SPE, 1990.

[2] K. Okutani, Y. Kuwabara and Y. H. Mori, "Surfactant Effects on Hydrate Formation in an Unstirred Gas/Liquid System: An Experimental Study Using Methane and Sodium Alkyl Sulfates," Chemical Engineering Science, Vol. 63, No. 1, 2008, pp. 183-194. doi:10.1016/j.ces.2007.09.012

[3] J. Yoslim, P. Linga and P. Englezos, "Enhanced Growth of Methane Propane Clathrate Hydrate Crystals with Sodium Dodecyl Sulfate, Sodium Tetradecyl Sulfate, and Sodium Hexadecyl Sulfate Surfactants," Journal of Crystal Growth, Vol. 313, No. 1, 2010, pp. 68-80.

doi:10.1016/j.jcrysgro.2010.10.009

[4] H. Ganji, M. Manteghian and H. R. Mofrad, "Effect of Mixed Compounds on Methane Hydrate Formation and Dissociation Rates and Storage Capacity," Fuel Processing Technology, Vol. 88, No. 9, 2007, pp. 891-895. doi:10.1016/j.fuproc.2007.04.010

[5] Y.-A. Kwon, J.-M. Park, K.-E. Jeong, et al., "Synthesis of Anionic Multichain Type Surfactant and Its Effect on METHANE GAS HYDRATE FORMATION," Journal of Industrial and Engineering Chemistry, Vol. 17, No. 1, 2011, pp. 120-124. doi:10.1016/j.jiec.2010.12.008

[6] H. Luo, C.-Y. Sun, Q. Huang, et al., "Interfacial Tension of Ethylene and Aqueous Solution of Sodium Dodecyl Sulfate (SDS) in or near Hydrate Formation Region," Journal of Colloid and Interface Science, Vol. 297, No. 1, 
2006, pp. 266-270. doi:10.1016/j.jcis.2005.10.013

[7] Y. Zhong and R. Rogers, "Surfactant Effects on Gas Hydrate Formation," Chemical Engineering Science, Vol. 55, No. 19, 2000, pp. 4175-4187. doi:10.1016/S0009-2509(00)00072-5

[8] S. L. Wang, M. J. Wei, et al., "Experimental Investigation on Promoting Effect of Composite Promoting Agents on Natural Gas Hydrate Formation," China Petroleum Processing and Petrochemical, Vol. 14, No. 1, 2012, pp. 2024.

[9] Q. Zhang, M. S. Pei and J. Zhang, "Study of Performance and Its Influencing Factors of Blends of Sodium Dodecyl Sulfate and Zwitterionic Surfactants," China Surfactant Detergent \& Cosmetics, Vol. 36, No. 2, 2006, pp. 69-72.
[10] B. Y. Zhu, P. Zhang, et al., "Investigation on Interaction between FC and HC Surfactants and Structure of Mixed Monolayer," China Surfactant Detergent \& Cosmetics, Vol. 12, No. 1, 1999, pp. 1-6.

[11] J. X. Xiao and G. Z. Zhao, "Surfactant Application Principle," Chemical Industry Press, Beijing, 2003.

[12] Y. L. Chen, Y. F. Zhang and Z. W. Hao, "Hydrocarbon-Carbon Fluorinated Surfactant Blends with the Performance," Guangdong Chemical Industry, Vol. 34, No. 167, 2007, pp. 24-26.

[13] H. W. Hao and G. K. Shi, "Origin7.5 Object-Lesson," China Electric Power Press, Beijing, 2000. 